\title{
ARTÍCULOS
}

\section{VIENTO DEL ESTE. LA URSS EN LA CULTURA MILITANTE DE LOS COMUNISTAS ESPAÑOLES (1917-1968)}

\author{
East wing. The USSR in the militant culture of Spanish communists
}

(1917-1968)

\author{
Eduardo Abad García* \\ Universidad de Oviedo \\ abadeduardo@uniovi.es \\ Orcid: 0000-0003-2748-5573
}

\section{Cómo citar este artículo/Citation:}

Eduardo Abad García, "Viento del este. La URSS en la cultura militante de los comunistas españoles (1917-1968", Hispania Nova, 19 (2021): 196 a 228.

DOI: $\underline{\text { https://doi.org/10.20318/hn.2021.5880 }}$
Copyright: (c) HISPANIA NOVA es una revista debidamente registrada, con ISSN 1138-7319 y Depósito Legal M 9472-1998. Los textos publicados están -si no se indica lo contrario- bajo una licencia Reconocimiento-Sin obras derivadas 3.0 España de Creative Commons. Puede copiarlos, distribuirlos y comunicarlos públicamente siempre que cite su autor y la revista y la institución que los publica y no haga con ellos obras derivadas. La licencia completa se puede consultar en: http://creativecommons.org/licenses/by-nd/3.0/es/deed.es
Resumen: Este artículo rastrea las principales características y manifestaciones de la influencia soviética en la cultura y la memoria comunista española. Para ello, se realiza un repaso general a través de su evolución histórica desde 1917 hasta 1968. Unas décadas en las que los comunistas sufrieron importantes transformaciones y en las que la visión que tenían de la URSS fue modulándose paulatinamente en función de las distintas coyunturas. La fidelidad a los valores que encarnaba la Unión Soviética se encontraba directamente vinculada a su repertorio cultural y a su propia autopercepción como militantes comunistas.

Palabras clave: Unión Soviética, comunismo, cultura política, militancia, memoria colectiva,

\section{PCE.}

Abstract: This article traces the main characteristics and manifestations of Soviet influence on Spanish communist culture and memory. For this, a general review is made through its historical evolution from 1917 to 1968. A few decades in which the communists underwent important transformations and in which the vision they had of the USSR was gradually modulating according to the different conjunctures. The fidelity to the values that the Soviet Union embodied was directly linked to their cultural repertoire and their own selfperception as communist militants.

Keywords: Soviet Union, communism, political culture, militancy, collective memory, PCE. 


\section{INTRODUCCIÓN}

Si hubo un suceso histórico en el s. XX que pudiera llegar a merecer ser calificado como un "acontecimiento monstruo" del movimiento obrero, sin lugar a dudas, ese fue la revolución soviética de octubre de 1917. El historiador francés Pierre Nora acuñó el concepto de "acontecimiento monstruo" para hacer referencia a determinados sucesos de carácter histórico que tendrían un especial impacto colectivo a medio y largo plazo, especialmente para la configuración de la memoria social ${ }^{1}$. La Revolución Rusa, rebautizada en el vocabulario comunista como la "Gloriosa Revolución de Octubre", cumplió con holgura todos estos requisitos. Este trascendental acontecimiento histórico también se convertiría para la posteridad en el principal "lugar de memoria" del comunismo moderno. Nora desarrolló esta última categoría a modo de "una noción abstracta, puramente simbólica, destinada a desentrañar la dimensión rememorada de los objetos, que pueden ser materiales, pero sobre todo inmateriales" ${ }^{2}$. En este sentido, resulta igualmente muy útil su utilización, ya que la URSS fue un referente moral y un mito movilizador que ilusionó a millones de personas en todo el planeta durante lo que Eric Hobsbawm denominó como "corto siglo XX"

Durante toda la historia del comunismo español, la Revolución de Octubre de 1917 destacó por lograr articular alrededor suyo uno de los principales elementos de la identidad comunista española ${ }^{4}$. El país de los soviets se convirtió, de esta manera, en la espina dorsal del cuerpo que representaba la cultura comunista en su conjunto, llegando

\footnotetext{
* Contratado posdoctoral "Severo Ochoa" para la formación en investigación y docencia del Principado de Asturias. Referencia: BP16028. Grupo de trabajo del Proyecto en que se integra el investigador: Del antifranquismo a la marginalidad: disidencias políticas y culturales en la Transición Española (Ref. HAR2016-79134-R).

${ }^{1}$ Pierre Nora, "L’evévénement monster", Communications, nº18 (1972), pp.162-172.

${ }^{2}$ Pierre Nora, "La aventura de Les lieux de memorie", Ayer, n’32 (1998), p. 32.

${ }^{3}$ Eric Hobsbawm, The age of extremes: The short twentieth century, 1914-1991, (Londres: Michael Joseph, 1994).

${ }^{4}$ Mayte Gómez, El largo viaje. Política y cultura en la evolución del Partido Comunista de España, 1920-1939, (Madrid: Ediciones de la Torre, 2005), pp. 54-84; Magdalena Garrido, Compañeros de viaje. Historia y memoria de las asociaciones de amistad hispano-soviéticas, (Murcia: Editum, 2009), pp. $97-$ 100; Francisco Erice, "El impacto de la Revolución rusa en el movimiento obrero español: el surgimiento del PCE", en Juan Andrade y Fernando Hernández (eds.), 1917. La Revolución rusa cien años después, (Madrid: Akal, 2017), pp.331-348.
} 
a constituirse como un factor identitario de primer orden ${ }^{5}$. Un "mito" que se encontraba en constante transformación y cuyas manifestaciones son rastreables bajo una mirada histórica de carácter sociocultural. La historiografía ha empleado con soltura el concepto de "mito soviético", no obstante, se hace necesario situar algunas cautelas respecto a su uso $^{6}$. Cuando se emplea el concepto de "mito", se hace referencia al universo simbólico construido en torno a la idealización de la URSS. Es decir, a algunos de los aspectos más representativos de la cultura política comunista: narrativas del pasado y políticas de memoria, construcción de los liderazgos carismáticos, las conmemoraciones o la existencia de una ritualidad vinculada a las prácticas de la cultura soviética. Sin embargo, eso no quiere decir que se tratase de un simple constructo falaz y que no existiera una base material sobre la cual se articulase este mito. En este sentido, son interesantes las reflexiones del escritor comunista Manuel Vázquez Montalbán, quien refiriéndose a la problemática que encontraba a la hora de hablar de los mitos en la cultura comunista escribía: "En ocasiones he empleado palabras como mito o símbolo [...] y he encontrado cierta resistencia a aceptarlas porque son palabras que implican irrealidad. Y no es eso. El mito es una suprarrealidad que siempre se basa en una apoyatura real, y el símbolo es una cúpula lingüística que alberga múltiples significados"?.

Continuando con esta perspectiva de análisis, se hace necesario abordar cuáles fueron las principales características de aquello que la historiografía ha caracterizado como el "mito soviético", para referirse a lo que representaba la URSS entre los

\footnotetext{
${ }^{5}$ Francisco Erice, "El 'orgullo' de comunista. Imagen, autopercepción, memoria e identidad colectiva de los comunistas españoles", en Manuel Bueno y Sergio Gálvez (eds.), Nosotros los comunistas: memoria, identidad e historia social, FIM, 2009, pp. 139-183.

${ }^{6}$ El concepto de mito soviético fue utilizado durante muchas décadas por el mundo politológico y periodístico con el objetivo atacar a la URSS dentro del contexto de la Guerra Fría, como un refuerzo a la pretendida superioridad del bloque capitalista liderado por los Estados Unidos. La historiografía lo ha usado de distintas maneras. Por ejemplo, el historiador anticomunista François Furet hablaba en los años noventa de la potencia mitológica del comunismo para mantener la ilusión retrotrayéndose constantemente a sus orígenes. Lo que actuaría a modo de engaño para sus seguidores, que lograrían mantener la ilusión pese a las "evidencias" de las catástrofes que estaba creando el comunismo en el mundo. Para más información ver: François Furet, El pasado de una ilusión: ensayo sobre la idea comunista en el siglo XX, (Madrid: EFE, 1995, p. 11. Otros historiadores más rigurosos como Giaime Pala o Tommaso Nencioni, lo han utilizado, incluso, para titular una de sus publicaciones, aunque sin adentrarse mucho en sus características. No obstante, sí que se puede deducir que su uso hace referencia a la construcción cultural de una cosmovisión política en la cual la URSS siempre tenía razón. Giaime Pala y Tommaso Nencioni (eds), El inicio del fin mito soviético, (Madrid: El Viejo Topo, 2008, p.185.

${ }^{7}$ Manuel Vázquez Montalbán, “Un servicio militante más de D. Ibárruri”, en Dolores Ibárruri, Memorias de Pasionaria (1939-1977), (Barcelona: Planeta), 1984, pp. 9-13.
} 
comunistas españoles. En este artículo se defiende la tesis de que, siguiendo la propuesta conceptual del sociólogo Pierre Bordieu, se puede calificar al país soviético como un "capital simbólico" de vital importancia para la cultura política comunista. Para Bordieu el "capital simbólico es cualquier propiedad (cualquier tipo de capital, físico, económico, cultural, social) cuando es percibido por agentes sociales cuyas categorías de percepción son tales, que permiten ser capaz de conocerlo (verlo) y reconocerlo, darle valor" ${ }^{\prime 8}$. Desde esta perspectiva se puede afirmar que, durante décadas, la URSS se fue convirtiendo para la militancia comunista en un capital simbólico capaz de proyectar sus sueños y utopías de un mundo mejor ${ }^{9}$. En un interesante trabajo sobre la influencia de la "metáfora soviética" en los comunistas italianos de la región emiliense, el historiador italiano Marco Fincardi aportaba algunas claves importantes que pueden trasladarse al caso español. Fincardi sostiene que, lejos de ser una continuación de la tradición católica, la "bolchevización cultural" que trajo consigo la revolución rusa, tendría su origen en un proceso de politización laica que se remontaría a una cultura proletaria cuyo origen se encuentra en el s. XIX ${ }^{10}$.

Sin embargo, el aparente éxito de este referente político y cultural acabaría entrado en crisis a finales de los años sesenta. A partir de esos años, el referente soviético pasaría a convertirse en un elemento de conflictividad y tensión entre las cúpulas y las bases de los partidos comunistas de Europa Occidental. El motivo de esta disputa se encuentra en la subsistencia de una visión idealizada de la URSS, hegemónica hasta finales de los años 60 , cuando comenzó a matizarse ${ }^{11}$. Dentro de esta dinámica global, el PCE no fue una excepción. La crisis de Checoslovaquia de 1968 se convirtió en el pistoletazo de salida para el surgimiento de varios movimientos disidentes de cariz ortodoxo en el seno del PCE. La importancia que encarnaba el país soviético estuvo presente en todas las olas de la historia de esta corriente ortodoxa, aunque su

\footnotetext{
${ }^{8}$ Pierre Bordieu, Raisons pratiques: Sur la théorie de l'action, (París: Seuil), 1994, p.116.

${ }^{9}$ Carme Molinero y Pére Ysàs, De la hegemonía a la autodestrucción. El Partido Comunista de España (1956-1982), (Barcelona: Crítica, 2017), p. 67.

${ }^{10}$ Mario Fincardi, C'era una volta il mondo nuovo. La metafora sovietica nello sviluppo emiliano, (Roma: Carocci, 2007), pp. 40 y 67.

${ }^{11}$ Carlos Rueda Laffond, Memoria Roja. Una historia cultural de la memoria comunista en España, 1936-1977, (Valencia: Universitat de València, 2018), p. 441.
} 
importancia fuese disminuyendo ${ }^{12}$. Estas divergencias evidenciaron la existencia de fuertes tensiones internas en la cultura política comunista fruto de las nuevas lecturas que realizaba la dirección del PCE sobre algunos elementos estructurales y estructurantes que conformaban su memoria colectiva ${ }^{13}$. De entre estos elementos, uno de los más importantes fue el relacionado con el papel asignado a la Unión Soviética en el imaginario colectivo de sus militantes ${ }^{14}$.

En referencia a esta cuestión, resulta muy importante tener presente otro concepto de uso obligado, que igualmente debe utilizarse con algunas reservas. Se trata del concepto de "doble lealtad", el cual también ha sido ampliamente empleado para hacer referencia al doble vínculo que adquiría la militancia comunista para con su partido y la Unión Soviética ${ }^{15}$. Sin embargo, es necesario recalcar que esta "lealtad" se desarrolló en parámetros meramente simbólicos, completamente alejados del esquematismo de la vieja sovietología. El contexto antagónico de la Guerra Fría, unido al antisovietismo del régimen franquista, polarizó las posturas respecto al país soviético en la sociedad española. Hasta 1968, como bien señala Giaime Pala, esta doble lealtad se podía resumir en "un apoyo sin reservas" a la URSS por parte de la inmensa mayoría de comunistas ${ }^{16}$.

Por consiguiente, el objetivo fundamental de este artículo es mostrar las principales características y manifestaciones de la influencia soviética en la cultura y la memoria comunista española. Además, se defenderá la tesis de que la fidelidad a esos valores que encarnaba la Unión Soviética se encontraba directamente vinculada al núcleo de su repertorio cultural y, especialmente, a su autopercepción como militantes

\footnotetext{
${ }^{12}$ El planteamiento teórico de las tres olas como metáfora de la disidencia ortodoxa puede verse en Eduardo Abad García, La disidencia ortodoxa en el comunismo español (1968-1989), tesis doctoral, Oviedo, Universidad de Oviedo, 2020.

${ }^{13}$ Emanuele Treglia "Un partido en busca de identidad. La difícil trayectoria del eurocomunismo español", Historia del presente, $\mathrm{n}^{\circ} 18$ (2011), pp. 25-28; "El PCE y el movimiento comunista internacional (1969-1977)", Cuadernos de Historia Contemporánea, n³7 (2015), pp. 248-253.

${ }^{14}$ Para el caso español y catalán ver: Giaime Pala, "Madrid-Barcelona-Roma-Moscou. El PCE, l'eurocomunisme i la crisi del PSUC (1968-1978)", Recerques, Historia, economía i cultura, no60 (2011), pp. 151-177; Eduardo Abad García, "Entre el internacionalismo y la disciplina de partido. Los comunistas asturianos ante la crisis de Checoslovaquia", Historia del Presente, no30 (2017), pp. 155-169. Para otros casos europeos que guardan características similares ver: Maud BRACKE, Which Socialism,Which Détente? West European Communism and the Czechoslovak Crisis of 1968, (Budapest: CEU Press, 2007) pp. 25-33.

${ }^{15}$ Franco de Felice, “Doppia lealtà e doppio stato", Studi Storici, no3 (1989), pp. 459-463.

${ }^{16}$ Giaime Pala, El inicio...op. cit., p. 185.
} 
comunistas. Para ello, se realiza un repaso general a través de su evolución histórica desde 1917 hasta 1968. Unas décadas en las que los comunistas sufrieron importantes transformaciones y en las que la visión militante de la URSS fue modulándose a lo largo de dos etapas diferenciadas.

\section{EL IMPACTO DE LA “GLORIOSA REVOLUCIÓN DE OCTUBRE”}

Al igual que en otras muchas partes de la geografía mundial, también en España se dejó sentir el fuerte impacto de la revolución soviética. Ya desde fechas muy tempranas el movimiento obrero español manifestó una profunda admiración por la Rusia Soviética. El creciente interés por las transformaciones producidas en el antiguo imperio zarista fue en aumento con el paso de los años, dando lugar a un importante proceso de recepción cultural ${ }^{17}$. Moscú pasaría así a convertirse en el centro de una potente red de solidaridad proletaria que unía a sectores de las clases populares de todo el planeta bajo un mismo imaginario colectivo ${ }^{18}$. La "bolchevización" de la cultura obrera española aumentó exponencialmente con la creación de la Internacional Comunista el 4 de marzo de 1919. Las manifestaciones cotidianas de esta sovietización cultural fueron numerosas y abarcaron un amplio abanico de representaciones. Un buen ejemplo se encuentra en el principal foco de ocio popular y socialización obrera, la taberna $^{19}$. Durante los años posteriores a la revolución rusa, los cambios en el país de Lenin se convirtieron en un tema recurrente de discusión y tertulia mientras se bebía o se jugaba a las $\operatorname{cartas}^{20}$. Esta infuencia se dejó sentir en otros muchos aspectos que afectaban a la vida cotidiana. En las pequeñas zonas donde los comunistas eran especialmente fuertes, por su presencia e influencia social, estos cambios fueron más representativos. Por ejemplo, algunos barrios o pueblos fueron renombrados

\footnotetext{
${ }^{17}$ Juan Avilés Farré, "El impacto de la revolución rusa en España, 1917-1922”, en Javier TUSELL, Juan Avilés y Rosa María Pardo, La política exterior de España en el siglo XX, (Madrid: Biblioteca Nueva, 2000), pp. 117-134; Juan Avilés Farré, La Fe que vino de Rusia, (Madrid: UNED, 1999).

18 Oleksa Drachewych, "The Communist Transnational? Transnational studies and the history of the Comintern", History Compass, Vol.17, n² (2019), pp. 2-5.

19 Jorge Uría, "La taberna en Asturias a principios del siglo XX. Notas para su studio", Historia Contemporánea, $\mathrm{n}^{\mathrm{o}} 5$ (1991), pp. 53-72.

20 Amaro del Rosal, "La taberna como centro de discusión política en Asturias (1914-1920)", Los cuadernos del Norte, nº14 (1982), Oviedo, Caja de Ahorros, pp.79-84.
} 
popularmente bajo el evocador topónimo de "la pequeña Rusia". Este fue el caso de Villa de Don Fadrique, un pequeño pueblo en la provincia de Toledo, el primero en tener un alcalde comunista durante la II República. Además, esta nueva cultura comunista trascendía a la cotidianeidad de sus seguidores, afectando incluso a las relaciones familiares. José Manzanero Marín, comunista fadriqueño, recordaba como “decenas de hijos nacidos en aquella época fueron inscritos en el Registro Civil de Villa de Don Fadrique con los nombres más eminentes de los dirigentes de la Revolución de octubre de 1917 en la U.R.S.S empezando por el camarada Lenin" ${ }^{21}$. La influencia de la nueva era que aventuraban los vientos provenientes del este soviético se dejó sentir también en otras clases sociales y sectores políticos ${ }^{22}$. Un buen ejemplo de ello se puede encontrar en la creación de una "Juventud Revolucionaria Roja" entre las filas de los jóvenes gijoneses de extracción republicana, influenciados por el hito soviético ${ }^{23}$. Otro escenario especialmente fecundo para la recepción del imaginario bolchevique fue el campo andaluz. Allí, las masas de jornaleros radicalizados por sus duras condiciones de trabajo recibieron las noticias provenientes de Rusia como una inequívoca señal de que la hora de la revolución por fin había llegado. Tuñón de Lara señalaba como junto a sus reivindicaciones laborales se podía observar en las multitudes el impacto moral de la revolución soviética. Incluso, fue en este contexto cuando aparecerían por vez primera representaciones de ese apoyo en forma de pintadas en las paredes de los cortijos. Frases como "Viva Lenin" o "Vivan los soviets" se convirtieron en elementos simbólicos de su nuevo repertorio cultural ${ }^{24}$. De hecho, la historiografia habla de Trienio Bolchevique (1918-1920) para referirse a las movilizaciones campesinas de Andalucía en esos años $^{25}$. El historiador que acuñaría este término, Juan Díaz del Moral, fue testigo directo de esa admiración por la Rusia soviética:

\footnotetext{
${ }^{21}$ José Manzanero, Páginas para la historia. Sobre la paz y el socialismo, (Valencia: Fernando Torres, 1983), p.16.

${ }^{22}$ Pablo Montes, "Obrerismo, republicanismo y reajuste de hegemonías al calor de la Revolución Rusa. Un análisis del caso catalán”, Nuestra Historia, nº (2007), pp.77-96.

${ }^{23}$ Francisco Erice, "El PCE en Asturias de los orígenes a la guerra civil", en Francisco Erice (coord.), Los comunistas en Asturias 1920-1982, (Oviedo: Trea, 1996), p. 41.

${ }^{24}$ Manuel Tuñón de Lara, La España del siglo XX, 1. La quiebra de una forma de Estado (1898-1931), (Barcelona: Laia, 1981), pp.101-102.

${ }^{25}$ Un completo estado de la cuestión se puede ver en: Adrián Sánchez Castillo, "One hundred years since the "Bolshevik Triennium" (1918-1920): agrarian unionism and collective actions during the Restoration crisis", Hispania Nova, n ${ }^{\circ} 18$ (2020), pp. 116-146.
} 
En mis frecuentes conferencias con trabajadores pude notar el proceso de entusiasmo y de ilusiones. Toda conversación derivaba inevitablemente hacia el tema ruso. Si se hablaba de siembras, surgía en el acto la pregunta: ¿Qué se siembra en Rusia? ¿Llueve mucho? ¿Cuánto produce una fanega de tierra? Si se hablaba de la temperatura, interrumpen en seguida: ¿En Rusia hace calor o frío? Y con cualquier motivo: ¿Hacia dónde cae Rusia? ¿Está muy lejos? ¿Cuántos días se tardarán en llegar andando? Rusia era una obsesión, no se caía de los labios ${ }^{26}$.

El modelo de la URSS como centro-guía de la revolución mundial fue consolidándose desde fechas muy tempranas. Este elemento funcionó como un gran foco de atracción social, sobrepasando la influencia real de la sección española de la Internacional Comunista, en esos momentos muy minoritaria dentro del movimiento obrero. En este sentido, son interesantes las reflexiones de Eric Hobsbawm sobre la admiración generalizada que profesaban las izquierdas hacia la Unión Soviética durante su primera etapa de existencia. Para el historiador inglés, la URSS llegó a actuar como un nexo de unión entre las distintas culturas políticas de la izquierda, ya que simbolizaba el "país de los trabajadores"27. Por su parte, es notorio que la construcción del imaginario colectivo comunista idealizaba fuertemente a la sociedad soviética como una utopía que se debía defender por todos los medios. Además, el referente soviético se convirtió en un reclamo muy eficiente para cohesionar a los partidarios de una solución radical ante las injusticias del capitalismo. De esta manera, la URSS se transformaría en un ejemplo ilusionante para miles de personas que creían que el éxito era posible pese a la adversidad. Por lo tanto, el valor más importante que representaba la URSS era que su mera existencia se había convertido en una confirmación de que el comunismo no sólo era una utopía, sino que era algo plausible ${ }^{28}$.

Pero el referente soviético también tenía otro mensaje importante para la clase obrera española: era necesario organizarse imitando la experiencia bolchevique. Eso suponía cambiar algunos de los viejos métodos organizativos y apostar por la bolchevización, entendida como "la extensión de un ideal de disciplina, un modelo de

\footnotetext{
26 Juan Díaz del Moral, Historia de las agitaciones campesinas andaluzas, (Madrid: Alianza, 1973 [1929]), p. 343.

${ }^{27}$ Eric Hobsbawm, Años interesantes. Una vida en el siglo XX, (Barcelona: Crítica, 2003), p. 91.

${ }^{28}$ Fernando Hernández, "El aliento de Lukanikos: percepciones de Octubre a lo largo de un siglo", en Juan Andrade y Fernando Hernández Sánchez, 1917....op.cit., p. 638.
} 
cuadro o la consolidación de una cultura internacional tendente a la homogeneidad" 29 . Hasta este momento el movimiento obrero español estaba caracterizado por una impronta mucho más asamblearia y espontaneísta de influencia libertaria. Aunque, también, en otras ocasiones manifestaba otras dinámicas más moderadas por la presencia socialista. Con la fundación el 14 de noviembre de 1921 del Partido Comunista de España (Sección española de la Internacional Comunista) se produjo el "mito fundacional" de los comunistas españoles ${ }^{30}$. Esta fecha pasó a ser una importante efeméride en la memoria de "el Partido", un referente central en la identidad de la militancia comunista. Este "lugar de memoria" estuvo directamente vinculado con la existencia de una identidad internacionalista que albergaba en sus entrañas la construcción de una nueva cultura política bajo los parámetros de la nueva "civilización socialista" que se extendía desde la URSS ${ }^{31}$. Naturalmente, a las clases populares no solo les llegaban buenas noticias. Con el avance de los años fueron aparecieron nuevos admiradores, pero también aumentó el número de detractores del referente soviético, lo que avivaba las controversias en torno a lo que estaba sucediendo en aquel país ${ }^{32}$. En este periodo tuvo lugar un creciente interés por todo lo soviético. Esto trajo consigo un cierto auge de los libros de viajes que tenían como destino la Rusia soviética y cuyo objetivo era informar de la situación vivida en este país ${ }^{33}$. Además, se produjo un aumento de la difusión de obras escritas por revolucionarios soviéticos como Lenin, Trotsky, Stalin o Bujarin, popularizando la imagen de ciertos liderazgos carismáticos. Tiempo atrás, la Unión Cultural Proletaria se había mostrado muy interesada en difundir todo este tipo de textos mediante la creación de la "Biblioteca El Comunista",34. En 1923

\footnotetext{
${ }^{29}$ Carlos Rueda Laffond, Memoria Roja... op. cit., p. 68.

${ }^{30}$ Dolores Ibárruri y otros, Historia del Partido Comunista de España, (París: Éditions Sociales,1960). p. 28.

${ }^{31}$ Carlos Rueda Laffond, Memoria Roja ...,op.cit., p. 202.

${ }^{32}$ Este es el caso de la CNT, que tras estar vinculada desde 1919 a las plataformas terceristas, rompió tales vínculos en 1921. Los motivos que generan esta ruptura se pueden leer en Ángel Pestaña, Informe de mi estancia en la URSS, (Madrid: ZYX, 1968), p. 49.

${ }^{33}$ Por citar solo algunos de los más relevantes: Julio Álvarez de Vayo, La Nueva Rusia, (Madrid: Espasa, 1926); Sofía Casanova, La revolución bolchevista: diario de un testigo, (Madrid: Biblioteca Nueva, 1920); Manuel Chávez Nogales, La vuelta a Europa en avión: un pequeño burgués en la Rusia Roja, (Madrid: Mundo Latino, 1929); Rodolfo Llopis, Cómo se forja un pueblo, La Rusia que yo he visto, (Madrid: España, 1929); Vicente Pérez Vich, Un militante de la C.N.T. en Rusia, (Barcelona: Imp. Industrial, 1932); Fernando de Los Ríos, Mi viaje a la Rusia soviética, (Madrid: Caro Ragio, 1921); Ramón J. Sender, Madrid-Moscú: notas de viaje, 1933-1934, (Madrid: Impr. de Juan Pueyo, 1934).

${ }^{34}$ Mayte Gómez, El largo viaje...op.cit., pp. 74-75.
} 
fue publicado un libro del dirigente asturiano Isidoro Acevedo, quien a finales del año anterior había viajado para asistir al IV Congreso de la Internacional Comunista. En sus páginas narraba la ilusión que le había producido su visita al nuevo país, al mismo tiempo que criticaba a sus oponentes. El texto llegaba a proponer toda una clasificación de los que Acevedo calificaba como "impugnadores":

A la Revolución Rusa le han salido varias clases de impugnadores. Los hay que la combaten ciegamente, sistemáticamente, sin pararse a analizarla. En este grupo podemos clasificar desde los reaccionarios más recalcitrantes hasta los anarquistas más exaltados, pasando por los que, blasonando de liberales, toda sociedad que no sea de tipo genuinamente capitalista hay que condenarla sin previo examen. Otro grupo lo constituyen los bienhallados con su existencia, los egoístas que temen las conmociones sociales por lo que de ellas salgan perdiendo. Forman otro grupo los que se alimentan de infundios y creen a pies juntillas los disparates que a diario propalan los periódicos que reciben informaciones de las Agencias montadas exclusivamente para desprestigiar la revolución rusa. Por último, constituyen otro grupo los que habiendo estado en Rusia no han comprendido aquella revolución ${ }^{35}$.

El avance del autoritarismo que trajo consigo la dictadura de Primo de Rivera tuvo como consecuencia una fuerte represión hacia los comunistas. Esta coyuntura, lógicamente, imposibilitó la realización de propaganda sobre la Unión Soviética, que tuvo que trasladarse a círculos clandestinos más cerrados ${ }^{36}$. Sin embargo, lejos de desaparecer, la URSS se fue consolidando como referente de primer orden: la "patria de todos los obreros del mundo". Esta concepción albergaba una fuerza simbólica en clave de movilización que sobrepasaba con creces la influencia real de la sección española de la IC. Además, este símbolo apelaba a la construcción de un nuevo imaginario colectivo, idealizando a la sociedad soviética. Así, por ejemplo, en 1924 el periódico comunista La Antorcha se hacía eco de los nuevos estándares ceremoniales de los bautizos soviéticos. Estos actos civiles eran presentados como muy superiores a los que estaban acostumbrados en la sociedad española. Entre los rasgos que se destacaban de esta nueva liturgia laica se encontraba la presencia de los dirigentes del partido, a modo de autoridades legítimas, y la elección del nombre del bautizado casi de forma asamblearia

\footnotetext{
${ }^{35}$ Isidoro Acevedo, Impresiones de un viaje a Rusia, (Oviedo: 1923), pp. 53-54.

${ }^{36}$ Mayte Gómez, El largo viaje...op.cit., pp. 104-105.
} 
entre los asistentes, lo que mostraba un radicalismo democrático que alcanzaba todos los aspectos de la vida cotidiana de la sociedad soviética ${ }^{37}$.

La llegada de la II República supuso la apertura de un periodo de gran crecimiento para la difusión de la cultura soviética. La creación de asociaciones de amistad contribuyó notablemente a propagar el ideal de la URSS como "faro de la humanidad", pero también como principal baluarte de la causa del antifascismo ${ }^{38}$. En 1933 fue creada la primera organización de amistad: la asociación Amigos de la Unión Soviética (AUS) ${ }^{39}$. Desde sus inicios, la AUS se configuró como una potente plataforma para la difusión de los logros soviéticos, justo en un momento de grave crisis estructural del capitalismo y auge de los fascismos en Europa. Estas asociaciones eran producto de un contexto internacional específico, en el cual la URSS trataba de proyectarse a los trabajadores del mundo, buscando extender al máximo la solidaridad para salir de su aislamiento. Era algo común que en las páginas de las revistas y folletos difundidos se insistiese en apelar a la unidad del proletariado mundial para defender la política exterior soviética de cualquier ataque. Al mismo tiempo, su propaganda publicitaba los logros sociales alcanzados, como muestra de que existía una alternativa real frente a la miseria en la que vivía la clase obrera de Europa Occidental ${ }^{40}$.

Otro potente medio de difusión cultural era la radio. Las emisiones dirigidas desde la Unión Soviética comenzaron a hablar en castellano a partir del 1 de agosto de $1932^{41}$. Se trataba de programas que servían para expresar las ideas comunistas y, especialmente, las expresiones culturales del mundo soviético. Esta herramienta fue vital para el crecimiento de las fuerzas comunistas, tal y como recoge un informe fechado en 1936 sobre las luchas llevadas a cabo en el periodo 1932-1936: "Estas emisiones han tenido gran importancia política para la vida, el trabajo y el desarrollo de nuestro Partido" 42 . Buena muestra de la fascinación que producía la cultura soviética se

\footnotetext{
37 “Un bautizo en Rusia soviética. En Ekaterinburgo", La Antorcha, 4-1-1924.

${ }^{38}$ Carlos Rueda Laffond, Memoria Roja...op.cit., pp. 204-207.

39 Magdalena Garrido, "Las relaciones culturales hispano-soviéticas contemporáneas a través de las asociaciones de amistad”, en Oscar Aldunate e Iván Fernández (coords.), I Encuentro de Jóvenes Investigadores en Historia Contemporánea de la AH, (Zaragoza: Universidad de Zaragoza), 2008, p. 6.

${ }^{40}$ Magdalena Garrido, Las relaciones entre España y la Unión Soviética a través de las Asociaciones de Amistad en el siglo XX., tesis doctoral, (Murcia: Universidad de Murcia, 2006), p.6.

41 “Hace 80 años radio Moscú empezó a hablar en español”, El Mundo, 31-07-2012.

${ }^{42}$ Informes sobre la actividad..., AHPCE, Fondo Nacionalidades y Regiones /Asturias, sig. 79/3.4.1.
} 
puede observar en el ejemplo del Bar Rojo, situado en la localidad de Sama (Asturias). Este espacio de socialización obrera se convirtió en un centro de difusión de la cultura bolchevique y por ello sufrió los golpes de la represión con varios registros y cierres. La historia de este bar resulta especialmente interesante, dado que contaba con un potente aparato de radio destinado a escuchar las emisiones radiofónicas en castellano de Radio Moscú Internacional. Atraídos por el reclamo soviético, todos los días se reunía allí un notable público. Los vínculos que se desarrollaron hacia el país soviético durante estas décadas se basaban en un sentimiento de ilusión colectiva ante la construcción de lo que consideraban un mundo nuevo. Estas conexiones transnacionales proyectaban sus anhelos en los supuestos logros del país, interiorizándolos como si fueran propios. De ahí, el afán de miles de trabajadores por saber más sobre lo que estaba pasando en este lejano país. Nuevamente, el ejemplo del Bar Rojo resulta muy ilustrativo. Según los informes recogidos por el PCE, una noche se llegarían a vivir momentos muy emotivos entre los obreros congregados, al lograr quedar segundos en un concurso que organizaba el Radio de los sindicatos de la URSS y cuyo premio eran sólo algunos libros soviéticos de propaganda. Como ya se ha explicado, un método muy importante para el crecimiento del mito soviético fueron las publicaciones periódicas y las ediciones de libros de dirigentes revolucionarios e, incluso, de información sobre aspectos muy diversos del país ${ }^{43}$. Además, la proliferación de una iconografía que ensalzaba a Lenin y Stalin mostraba "una simbiosis entre la idealización hagiográfica y los códigos figurativos propios del naturalismo" 44 . Otro eficiente método de proyección cultural se encontraba en el alto potencial propagandístico del "turismo revolucionario". El envío de trabajadores a la URSS (no necesariamente comunistas) fue algo común y era utilizado para que estos a su vuelta transmitiesen públicamente lo que habían visto y oído durante su viaje. De esta forma, se organizaron grandes actos en los que los propios trabajadores explicaban su experiencia, lo que supuso un excelente reclamo para reforzar las filas del $\mathrm{PCE}^{45}$.

\footnotetext{
${ }^{43}$ Miguel Vázquez Liñán, Propaganda política de la Unión Soviética en la Guerra Civil, española (19361939), tesis doctoral, (Madrid: Universidad Complutense de Madrid, 2003). Para más información sobre prensa enviada directamente de la URSS pp. 141-152 (capítulo La URSS en construcción y La Internacional Comunista) y para la prensa editada en España pp. 158-164.

${ }^{44}$ Carlos Rueda Laffond, Memoria Roja...op. cit., p. 126.

${ }^{45}$ Francisco Erice, "El PCE en Asturias...op. cit, p. 80.
} 
Estas redes transnacionales continuaron consolidándose en los años treinta, durante los cuales la URSS se convirtió en el mejor refugio para aquellos comunistas que huían de la represión. Esta fue la situación de Enrique Líster quien, tras un choque con la Guardia Civil en 1932, fue evacuado por el PCE hasta recalar en Moscú, donde vivió hasta 1935. Años más tarde, el propio Líster se encargaría de recalcar en su autobiografía cómo esta experiencia supuso un episodio transcendental en su vida militante por tres motivos. En primer lugar, porque allí se formó como cuadro comunista al poder estudiar en la escuela Lenin. En segundo lugar, porque fue donde se instruyó como militar, lo que se convirtió en su especialización dentro del partido durante toda su vida. En último lugar, y no por ello menos importante, el comunista gallego destacaba sobremanera su participación en la construcción del famoso metro de la capital soviética:

Esos tres años primeros años de mi estancia en la Unión Soviética fueron para mí una formidable escuela, sobre todo el año pasado en el "metro", donde trabajé y vivi con los trabajadores soviéticos presenciando cada día su inmenso heroísmo y su inagotable espiritu de sacrificio individual y colectivo. Ir a la Unión Soviética, vivir y trabajar con los hombres soviéticos era, desde hacía años, mi más ardiente deseo, que, por fin, veía convertido en realidad ${ }^{46}$.

Otro episodio importante de las relaciones de solidaridad España-URSS tuvo lugar en 1934. Ese año, muchos de los militantes que habían participado en el levantamiento revolucionario escogieron este país para refugiarse. Las muestras de solidaridad tuvieron, por tanto, varias dinámicas que acabaron por confluir en un mismo proceso de sinergia. Sin embargo, dentro de la construcción de estas redes globales destacó por su importancia el Socorro Rojo Internacional. Esta estructura transnacional, gracias a la cobertura soviética, llegó a desarrollar una gran labor asistencial hacia las familias que sufrieron la represión ${ }^{47}$. Este tipo de prácticas traspasaban lo meramente simbólico, llegando a la vida real de miles de personas que veían cómo los valores del "internacionalismo proletario" tenían un respaldo material. Para llevar a cabo su labor se construyó una vasta red que interconectaba a personas provenientes de culturas muy

\footnotetext{
${ }^{46}$ Enrique Líster Forján, Nuestra Guerra. Memorias de un luchador, Guadalajara, Silente, 2007, pp. 5152.

${ }^{47}$ Miguel Vázquez Liñan, Propaganda...op. cit., p. 113
} 
distintas, conformando una dinámica solidaria de ida y vuelta ${ }^{48}$. La URSS necesitaba a los obreros del mundo y los obreros del mundo necesitaban a la URSS. Resulta necesario destacar que fue mediante estas prácticas a través de las cuales se selló definitivamente la identidad global comunista que unía el este con el oeste bajo un imaginario común.

Un acontecimiento trascendental en la configuración de las relaciones entre los comunistas de España y los soviéticos fue la Guerra Civil española. La sublevación reaccionaria del 18 de julio de 1936 marcó el comienzo de una nueva etapa, profundizando las dinámicas de "heroización" que ya hemos expuesto con anterioridad. La experiencia de 1936-39 debe ser leída como un acontecimiento monstruo dentro de la memoria comunista española, caracterizada por ser una "guerra justa, patriótica y revolucionaria" ${ }^{49}$. La ayuda a la causa republicana mediante armamento y asesores aumentó notablemente el prestigio de la URSS entre los antifascistas españoles, especialmente, frente a la posición de otros países cuya actitud fue mucho más ambigua $^{50}$.

Además, durante el conflicto bélico, el PCE consiguió fortalecerse exponencialmente y convertirse en un partido respetado en el territorio controlado por la República. La madurez presentada por esta organización provocó un aumento muy notable de su militancia. A todo esto, hay que sumar el prestigio que aportaba la Unión Soviética como soporte internacional del partido ${ }^{51}$. Por otra parte, durante esta etapa se dieron muestras de lo que puede ser considerado como la "españolización” de la URSS. Un proceso desarrollado a través de la adaptación del simbolismo soviético en la clave frentepopulista que defendía el $\mathrm{PCE}^{52}$. La influencia del modelo soviético estuvo muy presente en algunas cuestiones claves, como en los intentos de unificación con el PSOE para dar lugar al "partido único proletario" siguiendo la imagen del PCUS. Aunque este

\footnotetext{
${ }^{48}$ Laura Branciforte, El Socorro Rojo Internacional (1923-1939). Relatos de la solidaridad antifascista, (Madrid: Biblioteca Nueva, 2011).

${ }^{49}$ Gilles Vergnon, “¿Historizar el antifascismo? Retorno sobre una cuestión”, en Aurora Bosch e Ismael Sanz (eds.), Izquierdas y derechas ante el espejo. Culturas Politicas en conflicto, (Valencia: Tirant le Blanch, 2015), pp. 349-350.

50 Juan Ambou, Los comunistas en la resistencia nacional republicana. La guerra en Asturias, el País Vasco y Santander, Madrid, Silente, 2010, p. 171.

${ }^{51}$ Para más información sobre este periódo ver: Fernando Hernández Sánchez, Guerra o revolución. El partido comunista de España en la Guerra Civil, (Barcelona: Crítica, 2010).

52 Carlos Rueda Laffond, Memoria Roja...op. cit., p. 273.
} 
proceso se vio truncado por las muchas diferencias que les separaban, uno de los elementos cohesionadores radicaba en el común reconocimiento del papel que ostentaba la URSS como líder de la causa socialista mundial. Un ejemplo se puede ver en uno de los primeros puntos de los pactos de unidad de acción:

Popularizaremos la gran ayuda prestada por la URSS y su gloriosa experiencia, que ha de ser nuestro norte, y combatiremos con las armas en la mano contra los que se atrevieran a atacarla. Llevaremos una lucha implacable contra todas las corrientes que quieran infiltrarse en el movimiento obrero para entorpecer la marcha de la unidad, sembrando el confusionismo por medio de frases extremistas, falsamente revolucionarias, queriendo apartar en estos momentos de la influencia del proletariado a los campesinos y a la pequeña burguesía, y pretendiendo desacreditar a la URSS, el gran país de la solidaridad. Lucharemos incansablemente contra todos los que desde fuera o desde dentro de nuestras organizaciones pretendan debilitar la unión sagrada de la clase obrera ${ }^{53}$.

El recrudecimiento de la guerra en España y el aumento de las muestras de solidaridad soviética dieron lugar a otro episodio importante en la memoria comunista. Se trató de la evacuación de varios contingentes de niños hacia la URSS con el objetivo de socorrerles mientras duraba el conflicto bélico, los conocidos como "niños de la Guerra" ${ }^{, 4}$. La Unión Soviética organizó una impresionante campaña de propaganda interna y externa con los huéspedes que había acogido ${ }^{55}$. Esta acción solidaria tuvo mucho eco en la memoria colectiva de los comunistas y actuó como un anclaje importante en la construcción de su narrativa del pasado. Las claves simbólicas más relevantes que rodean a estos hechos se pueden dividir en dos bloques. Por una parte, estas acciones se explicaban como un acto de piedad ante la barbarie de la guerra, lo que demostraba la superioridad moral de la civilización socialista. Por otra parte, también es necesario tener en cuenta que un sector importante de los familiares de los niños proyectaba sus propios anhelos en este viaje. Es decir, entendían este exilio temporal como una verdadera oportunidad para que estos jóvenes se formaran en un país que

\footnotetext{
53 "Pacto de unidad de acción entre socialistas y comunistas", Avance, Año VII $3^{\circ}$ Época, no 20,20 de enero de1937.

${ }^{54}$ Alicia Alted, María Encarna Nicolás Marín, Roger González Martell, Los Niños de la guerra de España en la Unión Soviética: de la evacuación al retorno (1937-1999), (Madrid: Fundación Largo Caballero, 1999); Inmaculada Colomina, Dos patrias, tres mil destinos. Vida y exilio de los niños de la guerra de España refugiados en la Unión Soviética, (Madrid: Fundación Largo Caballero, 2010).

${ }^{55}$ Ángel Luis Encinas Moral, Fuentes históricas para el estudio de la emigración española a la URSS (1936-2007), (Madrid: Exterior XXI, 2008), p.10.
} 
encarnaba los valores de una auténtica utopía. Este episodio permaneció en la memoria colectiva de los comunistas, tal y como recuerda Juan Ambou:

En cuanto a los niños, el Estado soviético los tomó a su cargo con carácter permanente, y a pesar de las tremendas dificultades de la guerra, y luego de la primera fase de la posguerra, les educó y abrió posibilidades de desarrollo que la mayor parte no hubiera podido soñar ni en su patria. Algunos de aquellos niños son hoy verdaderas personalidades con una alta calificación profesional. Hay muchos médicos, ingenieros, técnicos, profesores, economistas, artistas, etc.: algunos toman parte, con altas responsabilidades técnicas, en las grandes construcciones del comunismo ${ }^{56}$.

El triunfo de los sublevados en la guerra señaló el comienzo de un periodo verdaderamente complicado para los comunistas, marcado por la represión y el exilio. Sin embargo, durante esta etapa, el capital simbólico soviético continuó gozando de muy buena salud. Una parte de la militancia logró exiliarse en la URSS, aunque de forma menos numerosa que en otros países europeos o de América Latina. Sin embargo, destacados dirigentes como José Díaz, Pasionaria o Líster vivieron durante diferentes periodos en este país, lo cual reforzó las conexiones socioculturales entre España y la $\mathrm{URSS}^{57}$.

Un acontecimiento importante, que se llegaría a convertir en otro lugar de memoria omnipresente en el comunismo moderno, lo constituye la II Guerra Mundial. La URSS, donde vivía un colectivo destacable de españoles, llevó a cabo un grandísimo sacrificio económico y humano durante la contienda. De esta manera, la experiencia bélica frente al nazismo se convirtió en un periodo central dentro de la memoria cosmopolita comunista ${ }^{58}$. Uno de los lugares donde más visiblemente se puede observar su rastro es en las biografías de muchos militantes comunistas. Según la narrativa de algunas memorias, la participación española en la guerra dentro del Ejército Rojo habría sido un momento vital de suma importancia en su memoria personal. Su participación en lo que fue bautizado como la "Gran Guerra Patria" les volvía a hacer protagonistas dentro de una densa red transnacional en la cual se articulaba la identidad comunista. Su aportación a la resistencia y la victoria en la guerra les había provocado un profundo

\footnotetext{
${ }^{56}$ Juan Ambou, Los comunistas...op. cit., p. 121.

${ }^{57}$ Para más información sobre el exilio en la URSS ver: Matilde Eiroa, Españoles tras el Telón de Acero: El exilio republicano y comunista en la Europa socialista, (Madrid: Marcial Pons, 2018).

${ }^{58}$ Carlos Rueda Laffond, Memoria Roja...op. cit., p. 96.
} 
sentimiento de orgullo. Según este relato, sus autores se veían a sí mismos insertos en una de las grandes gestas de la clase obrera, la de la lucha contra el nazi-fascismo, cuyo primer episodio había tenido lugar en España ${ }^{59}$. Al mismo tiempo, este sacrificio era visto como la forma de devolver a la URSS la solidaridad prestada previamente. Incluso, se podría llegar a afirmar que supuso una especie de revancha poética frente a la guerra que habían perdido tan solo unos años antes:

Con nuestros hermanos soviéticos y con el mismo amor que defendimos nuestra patria, España, participamos en la defensa de Moscú, capital de la URSS, capital de los trabajadores de todo el mundo, capital del internacionalismo proletario. Estábamos en pleno invierno. El termómetro llegó a marcar cuarenta grados bajo cero. A toda costa el enemigo quería entrar en la capital. A todo precio la defendiamos. Como en Madrid, en aquel memorable noviembre de 1936, los españoles decíamos: “iNo pasarán!”. Y no pasaron ${ }^{60}$.

Para aquellos que proseguían resistiendo al fascismo en el interior, la Unión Soviética continuó representando las máximas aspiraciones de sus ideales a la vez que, de forma más pragmática, esta nación era considerada como una potente aliada. Según esta cosmovisión, la URSS representaba la única esperanza en los tiempos más duros. E1 país soviético podría volver a ofrecer su ayuda, esta vez liberando España del yugo de Franco. En este sentido, no resulta aventurado decir que la idea de que los tanques soviéticos podrían avanzar desde el este liberando toda Europa, incluida España, formó parte del imaginario colectivo de algunos comunistas españoles durante la II Guerra Mundial. Los informes de la organización del PCE en el interior de España confirman la idea de que algunos sectores confiaban en que la solución a la dictadura española vendría de la mano de la URSS: "la gente, en general, cree que la solución definitiva vendrá por parte de la URSS; es decir la revolución en Europa y, por consiguiente, en España. También, como consecuencia de la guerra europea y la intervención de la URSS al final para plantear y apoyar la revolución en los diversos países de Europa"61. Esta idea también caló hondo entre los militantes exiliados en Francia, quienes todavía

\footnotetext{
${ }^{59}$ Enrique Lister (1907-1982) 75 años. Una Historia, una lucha, (Madrid: FJCE, 1982, pp. 34-37.

${ }^{60}$ Relato de Ceferino Álvarez Rey en Juan Ambou, Los comunistas...op. cit., p. 163.

${ }^{61}$ Informe mecanografiado sobre la situación de España, AHPCE, Fondo Activistas/Madrid, caj. 92, carp. 36, p. 41
} 
en 1948 consideraban que la URSS y el propio Stalin se dedicarían a "liberar a los pueblos occidentales del yugo capitalista, sobre todo a Francia y a España”, ${ }^{\text {. }}$

\section{"BALUARTE DE LA PAZ MUNDIAL"}

El fin de la II Guerra Mundial dio paso a una nueva etapa en la cual se produjeron importantes transformaciones en la configuración internacional del movimiento comunista. La Guerra Fría trajo consigo grandes cambios en las formas de organización de los partidos y también en los valores que ahora encarnaba el referente soviético. En términos generales, la Unión Soviética continuó representando un pilar importante dentro del imaginario colectivo de los comunistas. Sin embargo, los cambios en las formas de coordinación mundial sobrevenidos con la desaparición de la Komintern y la Kominform marcaron el comienzo de profundas transformaciones que acabarían por afectar también a sus símbolos ${ }^{63}$. Por una parte, los partidos comunistas de Europa Occidental profundizaron una táctica política que decía buscar una "vía nacional al socialismo" en cada país. En este contexto, se modificó radicalmente la visión acrítica que existía en las cúpulas de algunos partidos occidentales respecto a la URSS, máxime cuando sus rivales políticos abusaban de esta figura para tratar de desacreditarles ${ }^{64}$. Sin embargo, por otra parte, estos cambios fueron alentados por la propia Unión Soviética, por lo que en sus inicios esta nueva táctica no debía chocar con sus intereses. La percepción generalizada entre la militancia comunista se mantuvo igual: estar contra la Unión Soviética era estar contra la principal herramienta para la causa de la clase obrera internacional. La historia oficial del Partido, escrita en 1960 por un grupo de dirigentes del PCE encabezados por Dolores Ibárruri, recogía esa narrativa del pasado glorificado de la URSS, el cual combinaba a la perfección con la llegada de una nueva etapa donde los partidos serían más autónomos:

\footnotetext{
62 S/n, 18/12/1948, Archive Departamental Haute-Garonne (ADHG), 5020W/24, citado en Fernando Hernández Sánchez, La Frontera Salvaje. Un frente sombrio del combate contra Franco (1944-1950), pp. 274-275.

${ }^{63}$ Willie Thompson, The Communist Movement Since 1945, Cornwall, Blackwell, 1998, p. 55

${ }^{64}$ Sobre el caso de esa evolución durante la segunda mitad del S. XX en el caso del PCE ver: Emanuele Treglia, "La elección de la vía nacional. La Primavera de Praga y la evolución política del PCE", Historia del Presente, $\mathrm{n}^{\circ} 16$ (2010), pp. 83-96.
} 
La titánica lucha del pueblo y del ejército soviéticos salvó a la humanidad de caer bajo el yugo del fascismo y fue el factor decisivo, la clave de la victoria de las Naciones Unidas. El prestigio internacional de la URSS creció en gigantescas proporciones. Las victorias de la URSS contribuyeron a vigorizar las fuerzas democráticas y socialistas de todo el mundo y a debilitar el sistema capitalista mundial.

En 1943, había sido disuelta la Internacional Comunista, después de haber cumplido su gran misión histórica: contribuir a crear y forjar partidos verdaderamente marxista-leninistas en casi todos los países de la tierra. El desarrollo y la madurez alcanzada por estos partidos hacian innecesario el mantenimiento de un centro dirigente internacional ${ }^{65}$.

Por su parte, la situación en el interior de España bajo la dictadura franquista poseía algunas características propias que merecen ser tenidas en cuenta para comprender por qué la URSS no solo continuó representando el referente supremo para la cultura comunista española, sino que fue creciendo y fortaleciéndose. En primer lugar, la propaganda del régimen ofreció durante cuarenta años una visión de la Unión Soviética como un modelo de país antagónico. Una sociedad que encarnaba unos valores transgresores frente a los que se alzaba la España católica y anticomunista. Para ello, se continuaba insistiendo en la falaz narrativa de la supuesta "sovietización" de la España republicana durante la contienda ${ }^{66}$. Además, la dictadura divulgó otro relato más moderno que se esforzaba por defender que esa dependencia para con el país de los soviets continuaba existiendo en los mismos términos. De este modo, se presentaba a los militantes comunistas que se organizaban en el interior de España como unos "agentes a sueldo de Moscú" que trataban de desestabilizar el país. Una de las principales obsesiones del régimen fue atacar constantemente a la URSS, agudizando sus fallos e inventándose calumnias para tratar de dinamitar el imaginario colectivo de la principal fuerza de la resistencia antifranquista ${ }^{67}$. Esta dinámica se vivió también en los países del occidente capitalista después de la II Guerra Mundial. La doctrina Truman trajo consigo una potente y constante campaña antisoviética que pasó por diferentes fases, estéticas y matices políticos durante las siguientes décadas. Encarnación Barranqueiro sostiene la tesis de que el régimen franquista, más que antimarxista en un sentido amplio, fue

\footnotetext{
${ }^{65}$ Dolores Ibárruri y otros, Historia del...op.cit., p.175.

${ }^{66}$ Matilde Eiroa, "El comunismo, sostén del anticomunismo. El Telón de Acero, España y la Guerra Fría", Cuadernos constitucionales de la Cátedra Fadrique Furió Ceriol, nº 45-46 (2004), pp. 199-210.

${ }^{67}$ Magdalena Garrido, "Las relaciones...op.cit., p.18.
} 
fundamentalmente antisoviético. Para ello, se basa principalmente en el hecho de que la estricta censura permitió la publicación en España de ensayos marxistas críticos con la URSS, mientras que la propaganda soviética fue duramente perseguida y totalmente clandestina hasta la Transición ${ }^{68}$.

En todo caso, parece más que comprobada la gran repercusión que adquirió la URSS en la conformación de la memoria e identidad colectiva de los comunistas españoles. Su importancia se puede rastrear fácilmente, al menos durante los primeros 30 años de franquismo, a través de la prensa política y los relatos biográficos ${ }^{69}$. Durante este período, los comunistas españoles construyeron una memoria colectiva en la que la Unión Soviética tuvo un papel muy destacado. En ella, este país aparecía representado como el símbolo más importante de la "épica heroicidad comunista". Un símbolo que contribuyó a articular la continuidad de una conciencia común que se extendió más allá de las vivencias de diferentes generaciones. Sin embargo, es necesario destacar cómo la transferencia de esa memoria asociada a la URSS y al hito fundacional de la revolución soviética sufrió un proceso de "indigenización" que se habría producido al adaptarla a la amplia fenomenología de prácticas llevadas a cabo por el PCE para la coyuntura española $^{70}$. Tal y como ha descrito el historiador Giaime Pala, el sistema de transmisión de ideas, juicios y valores en los espacios de sociabilidad militante actuaba en un marco intergeneracional, donde los recuerdos de la militancia más veterana influenciaban notablemente la cultura política de las nuevas generaciones comunistas ${ }^{71}$.

Otro acontecimiento muy importante en el contexto de la transfusión cultural PCUS-PCE tuvo lugar con la muerte de Stalin en 1953. Este fallecimiento supuso la desaparición de la persona que hasta ese momento había sido la cabeza visible del comunismo mundial. Una pérdida que, según escribiera Jorge Semprún en un poema a las pocas horas de su muerte, había dejado "huérfanos a todos los trabajadores de

\footnotetext{
${ }^{68}$ Encarnación Barranquero Texeira, "Propaganda soviética durante la transición”, comunicación en el VIII Seminario Internacional Nuestro Patrimonio Común: 1968-2008: ¿cuarenta años que cambiaron el mundo?, Cádiz, 4-7 noviembre de 2008.

${ }^{69}$ La totalidad de las autobiografías publicadas de militantes comunistas nombran, para bien o para mal, profusamente a la URSS. Respecto a las conmemoraciones sobre la revolución rusa en la prensa comunista y la construcción de una narrativa sobre el tema ver: Emanuel Treglia, "La Revolución de Octubre y su devenir histórico en el discurso del PCE: de la desestalinización a la perestroika", Nuestra Historia, $\mathrm{n}^{\mathrm{o}} .4$ (2017), pp. 107-122

${ }^{70}$ Carlos Rueda Laffond, Memoria Roja...op. cit., p. 25.

${ }^{71}$ Giaime Pala y Tommaso Nencioni (eds.), El principio del fin...op. cit., p. 186.
} 
España" ${ }^{, 72}$. Además, este acontecimiento propició la sucesión de todo un bloque de cambios bruscos en el panorama comunista internacional, que perdía uno de sus principales líderes históricos, y con él, el monolitismo que le había caracterizado hasta ese momento. También comenzó a aflorar un aumento de la tensión entre el PCE y el PCUS, fruto de la política exterior soviética. Por ejemplo, la aceptación a finales 1955 de la España de Franco en la ONU, gracias a la desaparición del veto de los soviéticos, trajo consigo una crisis en el seno del PCE, aunque finalmente no tuvo graves consecuencias $^{73}$. Las acusaciones del XX congreso del PCUS contra Stalin, acusado de fomentar el culto a la personalidad, conllevaron una política de damnatio memoriae contra su figura. Estos cambios, si bien supusieron algunas tiranteces iniciales, fueron asumidos por la mayoría de los comunistas sin excesivo problema. Esto no quiere decir que, en cierta manera, las explicaciones dadas por los nuevos dirigentes soviéticos lograran arrancar de raíz lo que Stalin había significado para los comunistas españoles ${ }^{74}$. Para algunos, fue difícil borrar completamente lo que un día había sido, volviendo al poema de Semprún, "el padre, el camarada [...] el jefe y el maestro"75. Un ejemplo de esta cuestión puede encontrarse en el testimonio de Líster, quien todavía a principios de los años 80 , hablaba en estos términos del bolchevique georgiano:

Pienso que Stalin es uno de los más grandes revolucionarios de todos los tiempos; opino que no es ni el dios que hemos adorado durante muchos años ni el monstruo que ha descrito Jruschov. Stalin - además de ser un hombre con sus virtudes y defectos-fue el dirigente máximo del Partido del primer Estado socialista que tuvo que dirigir la construcción del socialismo, la lucha contra los enemigos internos y exteriores, la industrialización, colectivización, la revolución cultural, la segunda guerra mundial, etc., en las terribles condiciones en las que las llevó. Pienso que con el tiempo Stalin ocupará en la historia del movimiento revolucionario $-y$ sobre todo comunista- el lugar que realmente le corresponde ocupar. Ni más ni menos $^{76}$.

\footnotetext{
${ }^{72}$ Jorge Semprún, Autobiografia de Federico Sánchez, (Barcelona: Planeta, 1977), pp. 146-147.

${ }^{73}$ Para ver la posición del PCE al respecto: "Sobre la entrada de España en la ONU. La política de coexistencia es una ayuda a las fuerzas antifranquistas y de paz", Mundo Obrero, enero 1956 y "La lucha del pueblo español contra el franquismo", Mundo obrero, febrero 1956.

${ }^{74}$ Para más información sobre la gestión de la desestalinización por parte del PCE ver: Francisco Erice, "El Partido Comunista de España, el giro de 1956 y la lectura selectiva del XX Congreso", Nuestra Historia, $\mathrm{n}^{\circ} 2$ (2016), pp. 66-88.

${ }^{75}$ Jorge Semprún, Autobiografia...op.cit., pp. 146-147.

${ }^{76}$ Enrique Líster Forján, Así destruyó Carrillo el PCE, (Madrid: Planeta, 1983), p. 116.
} 
Sin embargo, una de las mayores novedades del periodo de la Guerra Fría en cuanto a la narrativa e imagen proyectadas sobre la URSS tiene que ver con el pacifismo. Fue en este nuevo contexto donde se construyó y proyectó la idea de la URSS como un baluarte de la paz mundial ${ }^{77}$. Esta aportación a la cosmovisión comunista presentaba al país soviético como la única alternativa ante la agresividad del imperialismo que pretendía subyugar a los pueblos del mundo e incluso la total aniquilación de la humanidad mediante la bomba atómica. Se puede afirmar que este planteamiento ayudó a cohesionar, una vez más, a la militancia comunista en torno a la política exterior de la Unión Soviética en el nuevo marco global ${ }^{78}$. Asimismo, esta narrativa fue alimentada por las constantes intervenciones de los principales dirigentes comunistas. Por ejemplo, en 1947 Fernando Claudín declaraba en un mitin en Francia que, frente al imperialismo estadounidense, la URSS representaba la "verdadera salvadora de la democracia, de la libertad, de la independencia, de los trabajadores y de todos los pueblos"79.

Los comunistas españoles formaron parte las políticas pacifistas impulsadas por la Unión Soviética, participando en la creación del Consejo Mundial de la Paz (CMP) en $1949^{80}$. No es casualidad que el propio Enrique Líster tuviera un papel destacado en el CMP desde su creación ${ }^{81}$. Esta visión sobre la URSS y la paz mundial puede observarse fácilmente en la memoria orgánica que presentaba el PCE en 1960:

En el mundo se desarrollaba una gigantesca lucha de las fuerzas de la paz y de la guerra. La Unión Soviética y las democracias populares realizaban un gran esfuerzo para aliviar la tensión internacional; un movimiento de partidarios de la paz, sin precedentes por su amplitud, después de haber recogido millones de firmas contra la bomba atómica, abría campaña en pro de la solución negociada de

\footnotetext{
${ }^{77}$ Aunque esta visión es la antítesis de la política soviética en Occidente, esto no ha sido así en el Europa Oriental. Por ejemplo, ver: VV.AA., Historia de la Política exterior de la URSS, 1945-1970, (Moscú: Progreso, 1974).

${ }^{78}$ Aunque su influencia en el caso español no ha sido aún estudiada, a mi juicio pueden verse algunas analogías con el caso mexicano estudiado en: Jorge Octavio Fernández Montes, "Voces y llamamientos de la cultura por la paz. Génesis del pacifismo prosoviético de México en los albores de la Guerra Fría", Política y cultura, $\mathrm{n}^{\circ} 41$ (2014), México, pp. 7-29.

79 Fernando Hernández Sánchez, La frontera ...op. cit., p. 248.

${ }^{80}$ Sobre la creación del CMP y las políticas pacifistas de los comunistas ver: Geoffrey ROBERTS, "Averting Armageddon: The Communist Peace Movement, 1948-1956" en Setephen A. SMITH, The Oxford Handbook of the History of Communism, (Oxford: University of Oxford), 2014.

${ }^{81}$ El papel de Líster en el Consejo Mundial de la Paz de 1949 a 1974 se puede ver en: Enrique Líster Forján, Así destruyó...op. cit., pp. 213-252.
} 
los problemas litigiosos. Mientras tanto, los círculos agresivos del capital monopolista norteamericano, apoyándose en las fuerzas más reaccionarias de todo el mundo, procuraban agravar la tensión internacional, aceleraban la carrera armamentista y establecian en numerosos países bases militares destinadas a la agresión contra la $U R S S^{82}$.

Tras la muerte de Stalin aumentaron las tensiones entre China y la URSS, poniendo fin al monolitismo en el comunismo mundial. Esta crisis produjo en los comunistas españoles, como no podía ser de otra manera, un cierre de filas en torno al país soviético. La militancia se mostró dispuesta a respaldar incondicionalmente a los soviéticos frente a un referente exótico y poco conocido como era el de los comunistas $\operatorname{chinos}^{83}$. El argumentario escogido esta vez para defender la causa soviética se basaba en la defensa de la política de coexistencia pacífica del PCUS, planteada como una visión realista y efectiva ${ }^{84}$. Todo lo contrario que los comunistas chinos, que eran acusados de "infantilismo izquierdista", una de las peores acusaciones que un partido podía recibir dentro del universo simbólico comunista ${ }^{85}$. Por su parte, otros argumentos utilizados contra las posturas chinas estaban directamente relacionados con valores centrales dentro de la cultura militante, como eran el esfuerzo y la disciplina. Por eso, el discurso del PCE se mostraba frontalmente crítico contra aquellos que acusaban a la URSS de no estar interviniendo activamente para favorecer la revolución mundial:

En realidad, el increpador “¿Qué hace la Unión Soviética? Se está convirtiendo en el comodín de todos los impacientes y de todos los 'snobs, en la justificación de todas las pasividades y cobardías [...] La revolución mundial no es una cadena ininterrumpida y acelerada de éxitos [...] cada pueblo tiene que hacer su revolución, librar sus propias luchas y pagar el precio de su victoria. [...] Felicitémonos de que la URSS, gracias a ella misma, esté hoy en condiciones de ayudar a los demás. Pero no la pidamos que haga lo que solo nosotros-es decir cada pueblo, cada Partido, debe hacer ${ }^{86}$.

\footnotetext{
${ }^{82}$ Dolores Ibárruri y otros, Historia del...op.cit, p. 187.

${ }^{83}$ Para más información sobre la gestación de la crisis internacional ver: David Priestland, Bandera roja: historia politica y cultural del Comunismo, (Barcelona: Crítica, 2010), pp. 440-445; Brenda RUPAR, "El debate chino-soviético y la emergencia del maoísmo como corriente política diferenciada en el Movimiento Comunista Internacional”, Historia Contemporánea, n57 (2018), pp. 559-586.

${ }^{84}$ Vladimir Glebov, Maoísmo: Consignas y prácticas, (Moscú: Novosti, 1978), pp. 91-93.

${ }^{85}$ Las duras polémicas con los militantes del PCE (m-l) serán constantes desde la prensa del PCE. Por poner un ejemplo, en el caso asturiano fueron acusados de infiltración policial y literalmente de "ser peores que falange”. Ver Verdad, números de julio 1967, febrero 1968 y diciembre de 1970.

86 “QQué hace la Unión Soviética?”, Mundo Obrero, nº16, 01-07-1967.
} 
Pudiera parecer que, con el avance del tiempo y la búsqueda de una mayor autonomía, el PCE habría matizado la visión que proyectaba sobre la URSS. Sin embargo, esto distaba mucho de ser exactamente así. De hecho, las narrativas vertidas sobre la significación del referente soviético no sufrieron grandes modificaciones durante la década de los 60, siendo observable la reproducción de una mentalidad similar a la mostrada años atrás. Por ejemplo, el futuro dirigente asturiano Pedro Sanjurjo "Pieycha" narraba en sus memorias como gracias al interés por la URSS se decidiría a estudiar para radiotécnico:

Poco a poco me fui interesando sobre los ideales de la Revolución de Octubre en la Unión Soviética. Alguna hoja escrita con máquina de escribir había llegado a nuestras manos y releida muchas veces. Encerrado en mi habitación con una radio antigua que habia en casa comencé a sintonizar Radio Moscú en castellano [...] Se escuchaban con muchos ruidos pues la guardia civil contaba en Gijón con un emisor para crear interferencias. Esto me animaría para estudiar radio y poder así mejorar la recepción ${ }^{87}$.

Este elemento simbólico fue especialmente perceptible en lo relacionado con la memoria colectiva y su vinculación con la identidad comunista. Incluso el propio Carrillo, que más tarde destacaría por sus ácidas críticas a los soviéticos, expresaba a mediados de la década su admiración hacia la URSS en estos términos:

En toda mi formación de militante revolucionario, el respeto y el amor a la Unión Soviética, la admiración por la gran revolución socialista de Octubre, tienen una parte esencial. Yo pertenezco a esa generación que defendió Madrid, en 1936, iluminada y enardecida por el ejemplo de los bolcheviques en el Petrogrado rojo; de esa generación, muchos de cuyos componentes han caído en los pelotones franquistas fundiendo en el último momento en un mismo augurio, en un mismo jviva!, la confianza en la revolución española con la adhesión a la revolución rusa. Con esto quiero decir hasta qué punto me siento inclinado a tomar la defensa de la Unión Soviética, hasta qué punto rebotan sobre mi las críticas a los soviéticos cuando no son muy fundadas y serias ${ }^{88}$.

Otro ejemplo se puede encontrar en las páginas del órgano provincial del PCE en Asturias, Verdad, que en 1966 recogía en dos entregas las experiencias de la visita de un

\footnotetext{
${ }^{87}$ Pedro Sanjurjo, Memorias de Pedro Sanjurjo García "Pieycha”. De la lucha antifranquista al arte, Gijón, FAMYR, 2015, p.25.

88 "Declaraciones de Santiago Carrillo a Nuestra Bandera", Nuestra Bandera, n 47-48 de febrero-marzo de 1966, p. 18.
} 
minero asturiano a la Unión Soviética ${ }^{89}$. En la crónica de este viaje se describía con todo lujo de detalles la riqueza socializada del país, con especial hincapié en los logros tecnológicos de la minería soviética. Se trataba de un ejercicio clásico de reforzamiento de la cultura militante, que se esforzaba por empatizar con las esperanzas de la base obrera del partido e incluso de gran parte de proletariado asturiano en general. El país de los bolcheviques era aún visto por la mayoría de la militancia trabajadora como una sociedad a la que aspirar. Todavía a la altura de noviembre de 1967 el PCE mostraba un discurso muy similar al planteado décadas atrás:

En la sociedad socialista que alumbró la Revolución de Octubre el productor de la actividad laboral pertenece por entero a los trabajadores. En los últimos años los ingresos de los trabajadores soviéticos se han multiplicado por siete, y por nueve los de los campesinos, con una media semanal de 35 horas de trabajo en cinco dias [...] Los trabajadores soviéticos tienen libre acceso a la cultura y a todos los puestos de responsabilidad. [...] En la URSS no existe paro obrero porque los beneficios del trabajo que no perciben directamente los trabajadores son destinados a impulsar nuevas fuerzas de riqueza, y a toda clase de instalaciones que satisfagan las necesidades sociales y culturales de todo el pueblo [...] la productividad en la sociedad socialista se consigue, no a costa del esfuerzo físico de los trabajadores, sino mediante la sustitución del trabajo manual por el de la máquina. A la razón de humanizar el trabajo, de proporcionar una vida digna y feliz todo el pueblo responde el que el progreso científico, el nivel de conocimiento y la cultura de todo el pueblo, hayan constituido desde el comienzo de la Revolución de Octubre, la preocupación fundamental del Partido y del Estado soviético ${ }^{90}$.

Este tipo de argumentos fueron especialmente importantes, ya que uno de los principales motivos esgrimidos para defender a la URSS eran los diferentes logros que aquel país tenía en materia de salarios, educación, cultura o sanidad. Además, esta narrativa era presentada como antítesis de la penosa situación en la que vivía la clase obrera en España. La existencia de esa "superioridad soviética" constituía un reforzamiento imprescindible para mantener viva la ilusión colectiva en una meta final a imagen de la sociedad soviética y que funcionaba como horizonte regulador. Por tanto, décadas después, se continuaban reproduciendo los mismos factores y ejemplos que habían conformado el imaginario colectivo de los comunistas en torno a la Unión

\footnotetext{
${ }^{89}$ Verdad, números de septiembre y diciembre de 1966.

90 "Nueva era en la historia de la humanidad", Verdad, noviembre de 1967.
} 
Soviética desde sus inicios. Y todo esto a pesar del aumento de los roces fruto de las razones de Estado de algunas cuestiones de la política exterior soviética ${ }^{91}$. Por ejemplo, ya muy avanzada la década de los sesenta, el dirigente andalúz Ernesto Caballero pudo cumplir un sueño largamente esperado, viajar a la URSS. En sus memorias este comunista relata de qué forma el hecho de conocer a una Unión Soviética largamente idealizada no hizo sino reafirmar su creencia en un mundo mejor para todos ${ }^{92}$.

Lo cierto es que la influencia del referente soviético fue crucial para el desarrollo del universo simbólico del PCE y su abandono posterior, al menos para el caso de la militancia, fue más retórico que real ${ }^{93}$. Por eso, a pesar de las crisis políticas y las diferencias existentes, se puede afirmar que para muchos comunistas la URSS siempre fue un espejo donde mirarse. En palabras de un viejo comunista italiano, el símbolo soviético era considerado como un elemento donde "cada uno abocaba sueños, deseos, fantasías: una especie de ventana interior abierta al mañana, capaz de hacer olvidar las asperezas de la vida cotidiana" ${ }^{\text {94 }}$. Esto nos remite a la idea de que la URSS que formaba parte de su identidad, probablemente, tuviera poco que ver con la propia realidad soviética y más con su entorno cercano. Incluso es muy posible que en muchas ocasiones la actitud del país soviético no cumpliera las expectativas de los militantes comunistas $^{95}$. Sin embargo, como planteaba el veterano dirigente del PCE Santiago Álvarez, la URSS “era realmente, sin literatura, el faro, la esperanza, el ejemplo para millones de explotados en todo el mundo, para numerosos pueblos sometidos al imperialismo; y también, para científicos, escritores y artistas eminente de muchos países" "96. La URSS se había convertido en el andamio que sustentaba toda la estructura de la memoria cosmopolita comunista ${ }^{97}$. Un lugar de memoria que remitía a una

\footnotetext{
${ }^{91}$ Fernando Claudín, Eurocomunismo y socialismo, (Madrid: Siglo XXI, 1977), p. 35.

92 Ernesto Caballero Castillo, Vivir con memoria, (Valladolid: El Páramo), 2011.

${ }^{93}$ Sin embargo, el análisis meramente discursivo de la línea del PCE a este respecto mostraba un aumento paulatino en la dureza de las críticas emitidas. Al contrario que para la dirección, para un sector amplio de la militancia, la ruptura con este símbolo no acabaría nunca de producirse por completo. Emanuele Treglia, "La Revolución de Octubre...op.cit., pp.109-113.

${ }^{94}$ Ludovico Testa, La vita è lotta: storia di un comunista Emiliano, (Reggio Emilia: Diábasis, 2007), p. 37.

95 Encarnación Barranquero Texeira, "El Partido Comunista...op. cit., p. 96.

96 Simón Sánchez Montero, El futuro se llama libertad ("Perestroika” y socialismo), (Madrid: El País, 1988V, p. 28.

${ }^{97}$ Carlos Rueda Laffond, Memoria Roja...op.cit., p. 90.
} 
narrativa del ayer en la cual se idealizaba la historia soviética en claves épicas ${ }^{98}$. Esta codificación simbólica está relacionada con su transformación en uno de los principales soportes de su autopercepción, que sólo se volvería algo conflictivo tras la crisis de Checoslovaquia de 1968. Aun así, los intentos de abandonar todo este fuerte simbolismo, llevados a cabo por la dirección del PCE, acabarían teniendo graves consecuencias para parte de la militancia comunista, especialmente, en la base obrera del partido y los más veteranos. Los problemas surgieron cuando la dirección del PCE se distanció de este mito buscando dar mayor credibilidad a las propuestas tácticas de su partido entre sus posibles aliados ${ }^{99}$. Estos cambios fueron acogidos con recelo al suponer una ruptura con una parte importante de la identidad comunista que representaba el legado de la URSS. Tan solo con la entrada de nuevas generaciones de militantes, menos ligadas a la "sovietización" de su memoria colectiva, fue posible abandonar parcialmente esa mitificación. No obstante, este proceso no estaría exento polémicas y conflictos, pese a ser implantado de manera bastante paulatina ${ }^{100}$.

Pese a su marginación, este capital simbólico lograría sobrevivir posteriormente. De hecho, sirvió para cohesionar el rechazo a las nuevas políticas del "carrillismo" mediante diversas olas de disidencia ortodoxa. Nuevamente, la razón de esa resistencia hay que buscarla en la firme conexión existente entre la Unión Soviética y la cultura militante del PCE. Máxime en un momento en el que la adhesión incondicional a la Unión Soviética aún formaba parte del ADN de los comunistas ${ }^{101}$. Durante los años setenta y ochenta, este país continuaría representando un anclaje importante en el imaginario colectivo de los comunistas ortodoxos ${ }^{102}$.

\section{CONCLUSIONES}

De lo visto y analizado en este artículo es posible extraer varias conclusiones. En primer lugar, ha quedado patente que durante décadas se construyó y reforzó un modelo

\footnotetext{
${ }^{98}$ Juan Ambou, Los comunistas..., op.cit., p. 170.

${ }^{99}$ Francisco Erice, "Santiago Carrillo y el partido del antifranquismo (1955-1975)", Historia del presente, n'24 (2014), p. 11.

${ }^{100}$ Manuel Azcárate, Crisis del eurocomunismo, (Barcelona: Ed. Argos Vergara, 1982), p. 66.

${ }^{101}$ Francisco Erice, "El 'orgullo' de ser comunista...op. cit., pp. 149-151.

${ }^{102}$ Ver: Eduardo Abad, "El otoño de Praga. Checoslovaquia y la disidencia ortodoxa en el comunismo español (1968-1989)", Historia Contemporánea, no61 (2019), pp. 971-1003. DOI: https://doi.org/10.1387/hc. 19542
} 
de memoria colectiva comunista que tenía como un destacado eje vertebrador a la Unión Soviética. En su primera etapa, el comunismo estaba directamente asociado a los sucesos revolucionarios de Rusia. La revolución de octubre trajo consigo una ruptura con todas las culturas políticas existentes y se convirtió en el principal reclamo para la nueva causa. Este acontecimiento monstruo se convertiría en un importante lugar de memoria para los partidos comunistas. Además, la verdadera fuerza del PCE durante estos años residía en su vínculo directo con la URSS. Por eso se potenció la propaganda de los éxitos sociales y económicos logrados por los bolcheviques. A esto hubo que sumar la solidaridad mostrada por la unión de repúblicas, que se convirtió en tierra de refugio y de formación para cientos de españoles. El estallido de la Guerra Civil supondría otro importante episodio dentro de las relaciones hispano-soviéticas. Posteriormente, el triunfo de los sublevados traería consigo una dura persecución hacia los comunistas. De esta manera, las redes de solidaridad de fortalecieron exponencialmente. En ese contexto, el odio que el régimen vertía diariamente contra la URSS actuó como un refuerzo respecto a este sentimiento de admiración. Como consecuencia, durante estas décadas la Unión Soviética fue interiorizada como un mito vivo que representaba los anhelos y esperanzas de la militancia comunista. Como consecuencia, la URSS se convirtió en un capital simbólico que tenía un objetivo movilizador. Por lo tanto, los militantes, al asumir como propio de su cultura ese mito, se comprometían a contribuir personalmente a la revolución mundial que habían empezado los trabajadores soviéticos. Según esta visión, la meta de los comunistas españoles debía ser la realización de la revolución en su propio país aprendiendo de las lecciones de la historia soviética. Para ello, debían desarrollar una táctica flexible y una estrategia ortodoxa, entre la que destacaba la sintonía con la Unión Soviética.

En una segunda etapa, aparecieron nuevos elementos que reconfiguraron las características de su simbolismo. El nuevo contexto de la Guerra Fría y la amenaza nuclear situaron la lucha por la paz como un objetivo prioritario. De esta manera, la URSS pasaría a representarse como la mejor herramienta pacifista. Sin embargo, los sentimientos de gratitud y admiración hacia lo que simbolizaba este país o su historia se mantuvieron inalterados. Es más, las narrativas militantes y partidarias continuaron empleando los mismos factores que habían utilizado durante las décadas anteriores. La URSS fue un componente omnipresente en la cultura militante de los comunistas españoles. Este símbolo no solo tuvo mucho peso en las generaciones más veteranas, 
sino también en las jóvenes. Esto fue posible gracias a la existencia de una continuidad intergeneracional durante el curso de su formación de una conciencia común. Un complejo proceso donde se fabricó un imaginario colectivo que se extendía más allá de las vivencias personales. Sin embargo, ese simbolismo fue adaptado a las tradiciones de la cultura local. Tanto la simbología como la ritualidad de los comunistas españoles fueron erigidas sobre una amplia cultura política cargada de alegorías soviéticas. A su vez, los dirigentes soviéticos, convertidos en líderes indiscutibles, pasarían a encarnar los principales liderazgos carismáticos de la cosmovisión militante.

No hay que olvidar que lo que se ha conocido como el mito soviético se sustentaba sobre unas bases materiales, las cuales produjeron un amplio repertorio de elementos que nutrieron la narrativa de la cultura política comunista. La solidaridad vertida por la Unión Soviética durante varias etapas reforzó ese vínculo e insertó a la militancia dentro de unas redes culturales de carácter transnacional. Estas redes compartían una cosmovision ideológica común cuyo principal centro productor se encontraba en Moscú. Sin embargo, cuando comenzaron las transfromaciones moleculares de esa identidad en el PCE, la URSS pasaría a simbolizar un importante reclamo para futuras disidencias ortodoxas.

\section{BIBLIOGRAFÍA}

Abad García, Eduardo, "Entre el internacionalismo proletario y la disciplina de partido. Los comunistas asturianos ante la crisis de Checoslovaquia", Historia del Presente, no30, 2017, pp. 155-169.

--“El otoño de Praga. Checoslovaquia y la disidencia ortodoxa en el comunismo español (1968-1989)", Historia Contemporánea, n61, 2019, pp. 971-1003. DOI: https://doi.org/10.1387/hc. 19542

--La disidencia ortodoxa en el comunismo español (1968-1989), tesis doctoral, Oviedo, Universidad de Oviedo, 2020.

Acevedo, Isidoro, Impresiones de un viaje a Rusia, Oviedo, 1923.

Alted, Alicia, María Encarna Nicolás Marín, Roger González, Martell, Los Niños de la guerra de España en la Unión Soviética: de la evacuación al retorno (19371999), Madrid, Fundación Largo Caballero, 1999.

Álvarez del Vayo, Julio, La Nueva Rusia, Madrid, Espasa, 1926.

Ambou, Juan, Los comunistas en la resistencia nacional republicana. La guerra en Asturias, el País Vasco y Santander, Madrid, Silente Memoria Histórica, 2010. 
Avilés Farré, Juan, La Fe que vino de Rusia, Madrid, UNED, 1999.

-- "El impacto de la revolución rusa en España, 1917-1922", en Tusell, Javier, Avilés, Juan y Pardo, Rosa María, La política exterior de España en el siglo XX, Madrid, Biblioteca Nueva, 2000, pp. 117-134.

Azcárate, Manuel, Crisis del eurocomunismo, Barcelona, Ed. Argos Vergara, 1982.

Barranquero Texeira, Encarnación, "Propaganda soviética durante la transición", comunicación en el VIII Seminario Internacional Nuestro Patrimonio Común: 1968-2008: ¿cuarenta años que cambiaron el mundo?, Cádiz, 4-7 noviembre de 2008.

-- "El Partido Comunista de España y la propaganda soviética", Revista de Historia Actual, $\mathrm{n}^{\circ} 6$ (2008), pp. 89-102.

Bordieu, Pierre, Raisons pratiques: Sur la théorie de l'action, París, Seuil, 1994

Bracke, Maud Anne, Which Socialism, Which Détente? West European Communism and the Czechoslovak Crisis of 1968, Budapest, CEU Press, 2007.

Branciforte, Laura, El Socorro Rojo Internacional (1923-1939). Relatos de la solidaridad antifascista, Madrid, Biblioteca Nueva, 2011.

Casanova, Sofía, La revolución bolchevista: diario de un testigo, Madrid, Biblioteca Nueva, 1920.

Chávez Nogales, Manuel, La vuelta a Europa en avión: un pequeño burgués en la Rusia Roja, Madrid, Mundo Latino, 1929.

Claudín, Fernando, Eurocomunismo y socialismo, Madrid, Siglo XXI, 1977.

Colomina, Inmaculada, Dos patrias, tres mil destinos. Vida y exilio de los niños de la guerra de España refugiados en la Unión Soviética, Madrid, Fundación Largo Caballero, 2010.

De Felice, Franco, "Doppia lealtà e doppio stato", Studi Storici, no3 (1989), pp. 493 563.

Del Rosal, Amaro, "La taberna como centro de discusión política en Asturias (19141920)", Los cuadernos del Norte, nº14 (1982), Oviedo, Caja de Ahorros, pp.7984.

De los Ríos, Fernando, Mi viaje a la Rusia soviética, Madrid, Caro Ragio, 1921.

Díaz del Moral, Historia de las agitaciones campesinas andaluzas, Madrid, Alianza, 1973 [1929].

Drachewych, Oleksa, "The Communist Transnational? Transnational studies and the history of the Comintern", History Compass, vol.17, n'2 (febrero 2019).

Eiroa, Matilde, "El comunismo, sostén del anticomunismo. El Telón de Acero, España y la Guerra Fría", Cuadernos constitucionales de la Cátedra Fadrique Furió Ceriol, no 45-46 (2004), pp. 199-210.

-- Españoles tras el Telón de Acero: El exilio republicano y comunista en la Europa socialista, Madrid, Marcial Pons, 2018.

Encinas Moral, Ángel Luis, Fuentes históricas para el estudio de la emigración española a la URSS (1936-2007), Madrid, Exterior XXI, 2008. 
Erice Sebares, Francisco, "El PCE en Asturias de los orígenes a la guerra civil", en Francisco Erice, Francisco (coord.), Los comunistas en Asturias 1920-1982, Oviedo, Trea, 1996, pp. 41-84.

-- "El 'orgullo' de ser comunista. Imagen, autopercepción, memoria e identidad colectiva de los comunistas españoles”, en Bueno, Manuel y Gálvez, Sergio (eds.), Nosotros los comunistas: memoria, identidad e historia social, Fundación de Investigaciones Marxistas, 2009, pp. 139-183.

-- Santiago Carrillo y el partido del antifranquismo (1955-1975)", Historia del presente, no24 (2014), pp. 43-58.

-- "El Partido Comunista de España, el giro de 1956 y la lectura selectiva del XX Congreso", Nuestra Historia, no2 (2016), pp. 66-88.

-- "El impacto de la Revolución rusa en el movimiento obrero español: el surgimiento del PCE”, en Andrade, Juan y Hernández Sánchez, Fernando, 1917. La Revolución rusa cien años después, Madrid, Akal, 2017, pp. 331-358.

Hernández Sánchez, Fernando, Guerra o revolución. El partido comunista de España en la Guerra Civil, Barcelona, Crítica, 2010.

-- Los años de plomo. La reconstrucción del PCE bajo el primer franquismo (19391953), Barcelona, Crítica, 2015.

-- "El aliento de Lukanikos: percepciones de Octubre a lo largo de un siglo", en Andrade, Juan y Hernández Sánchez, Fernando, 1917. La Revolución rusa cien años después, Madrid, Akal, 2017, pp. 635-638.

Ibárruri, Dolores y otros, Historia del Partido Comunista de España, París, Éditions Sociales, 1960.

Hobsbawm, Eric J., The age of extremes: The short twentieth century, 1914-1991, Michael Joseph. London, 1994.

-- Años interesantes. Una vida en el siglo XX, Barcelona, Crítica, 2003.

Fernández Montes, Jorge Octavio, "Voces y llamamientos de la cultura por la paz. Génesis del pacifismo prosoviético de México en los albores de la Guerra Fría", Política y cultura, no41 (2014), México, pp.7-29.

Fincardi, Mario, C'era una volta il mondo nuovo. La metafora sovietica nello sviluppo emiliano, Roma, Carocci, 2007.

Furet, François, El pasado de una ilusión: ensayo sobre la idea comunista en el siglo XX, Madrid, EFE, 1995.

Garrido, Magdalena, Las relaciones entre España y la Unión Soviética a través de las Asociaciones de Amistad en el siglo XX, tesis doctoral, Murcia, Universidad de Murcia, 2006.

-- "Las relaciones culturales hispano-soviéticas contemporáneas a través de las asociaciones de amistad", en Aldunate, Oscar Aldunate León e Heredia, Iván (coords.), I Encuentro de Jóvenes Investigadores en Historia Contemporánea de la $A H$, Universidad de Zaragoza, 2008.

-- Compañeros de viaje. Historia y memoria de las asociaciones de amistad hispano-soviéticas, Murcia, Editum, 2009. 
Glebov, Vladimir, Maoísmo: Consignas y prácticas, Moscú, Novosti, 1978.

Gómez, Mayte, El largo viaje. Política y cultura en la evolución del Partido Comunista de España, 1920-1939, Madrid, Ediciones de la Torre, 2005.

Líster Forján, Enrique, Enrique, Así destruyó Carrillo el PCE, Madrid, Planeta, 1983.

-- Nuestra Guerra. Memorias de un luchador, Guadalajara, Silente, 2007.

Llopis, Rodolfo, Cómo se forja un pueblo, La Rusia que yo he visto, Madrid, España, 1929.

Manzanero Marín, José, Páginas para la Historia. Sobre la paz y el socialismo, Santander, Fernando Torres, 1983.

Molinero, Carme y Pere Ysàs, De la hegemonía a la autodestrucción. El Partido Comunista de España (1956-1982), Barcelona, Crítica, 2017.

Montes, Pablo, "Obrerismo, republicanismo y reajuste de hegemonías al calor de la Revolución Rusa. Un análisis del caso catalán”, Nuestra Historia, nº, 2007, pp.77-96.

Nora, Pierre, “L’evévénement monstrer”, Communications, nº18, 1972, pp.162-172.

-- "La aventura de Les lieux de memorie", Ayer, n³2, 1998, pp.17-34.

Pala, Giaime, "Madrid-Barcelona-Roma-Moscou. El PCE, l'eurocomunisme i la crisi del PSUC (1968-1978)", Recerques, Historia, economía i cultura, nº6, 2011, pp.151-177.

Pala, Giaime y Tommaso Nencioni, (eds.) El inicio del fin del mito soviético, Madrid, El Viejo Topo, 2008.

Pérez Vich, Vicente, Un militante de la C.N.T. en Rusia, Barcelona, Imp. Industrial, 1932.

Pestaña, Ángel, Informe de mi estancia en la URSS, Madrid, ZYX, 1968.

Priestland, David, Bandera roja: historia política y cultural del Comunismo, Barcelona, Crítica, 2010.

Roberts, Geoffrey, "Averting Armageddon: The Communist Peace Movement, 19481956" en A. Smith, The Oxford Handbook of the History of Communism, Oxford, University of Oxford, 2014.

Rueda Laffond, José Carlos, Memoria Roja: Una historia cultural de la memoria comunista en España, 1936-1977, Valencia, Universitat de València, 2018.

Rupar, Brenda "El debate chino-soviético y la emergencia del maoísmo como corriente política diferenciada en el Movimiento Comunista Internacional", Historia Contemporánea, $\mathrm{n}^{\circ} 57$ (2018), pp. 559-586.

Sánchez Castillo, "One hundred years since the "Bolshevik Triennium" (1918-1920): agrarian unionism and collective actions during the Restoration crisis", Hispania Nova, $\mathrm{n}^{\mathrm{o}} 18$ (2020), pp. 116-146.

Sánchez Montero, Simón, El futuro se llama libertad ("Perestroika" y socialismo), Madrid, El País, 1988. 
Sanjurjo, Pedro, Memorias de Pedro Sanjurjo García "Pieycha". De la lucha antifranquista al arte, Gijón, FAMYR, 2015.

Semprún, Jorge, Autobiografía de Federico Sánchez, Barcelona, Planeta, 1977.

Sender, Ramón J., Madrid-Moscú: notas de viaje, 1933-1934, Madrid, Impr. de Juan Pueyo, 1934.

Testa, Ludovico, La vita è lotta: storia di un comunista Emiliano, Diabásis, Reggio Emilia, 2007.

Thompson, Willie, The Communist Movement Since 1945, Cornwall, Blackwell, 1998.

Treglia, Emanuele, "La elección de la vía nacional. La Primavera de Praga y la evolución política del PCE”, Historia del Presente, n¹6, 2010, pp. 83-96.

-- "Un partido en busca de identidad. La difícil trayectoria del eurocomunismo español”, Historia del presente, $\mathrm{n}^{\mathrm{0}} 18,2011$, pp. 25-41.

-- "E1 PCE y el movimiento comunista internacional (1969-1977)", Cuadernos de Historia Contemporánea, $\mathrm{n}^{0} 37$ (2015), pp. 225-255. DOI: https://doi.org/10.5209/rev_CHCO.2015.v37.50993

- "La Revolución de Octubre y su devenir histórico en el discurso del PCE: de la desestalinización a la Perestroika", Nuestra Historia, nº (2017), pp.107-122.

Tuñon de Lara, Manuel, La España del siglo XX, 1. La quiebra de una forma de Estado (1898-1931), Barcelona, Laia, 1981

Uría, Jorge, "La taberna en Asturias a principios del siglo XX. Notas para su studio", Historia Contemporánea, no5 (1991), pp. 53-72.

Vázquez Liñán, Miguel, Propaganda política de la Unión Soviética en la Guerra Civil, española (1936-1939), tesis doctoral, Madrid, Universidad Complutense de Madrid, 2003.

Vázquez Montalbán, Manuel, "Un servicio militante más de Dolores Ibárruri”, en Ibárruri, Dolores, Memorias de Pasionaria (1939-1977), Barcelona, Planeta, 1984, pp. 9-13.

Vergnon, Gilles, “HHistorizar el antifascismo? Retorno sobre una cuestión”, en Bosch, Aurora e Sanz, Ismael (eds.), Izquierdas y derechas ante el espejo. Culturas Políticas en conflicto, Valencia, Tirant le Blanch, 2015, pp.349-350.

VV.AA., Historia de la Política exterior de la URSS, 1945-1970, Moscú, Progreso, 1974. 